\title{
Correlação fenotípica entre caracteres agronômicos em população segregante de mandioca de mesa ${ }^{1}$
}

\author{
Eduardo Alano Vieira ${ }^{2}$, Josefino de Freitas Fialho ${ }^{3}$, Luiz Joaquim Castelo Branco Carvalho 4 \\ http://dx.doi.org/10.1590/0034-737X201461040011
}

\section{RESUMO}

Um dos principais entraves do melhoramento genético de mandioca é a dificuldade de seleção precoce de indivíduos superiores nas primeiras gerações do melhoramento. Dessa forma, o objetivo deste trabalho foi estimar correlações fenotípicas entre caracteres agronômicos de interesse em uma população segregante de mandioca nas gerações de propagações vegetativa e sexual e entre as duas, a fim de contribuir na geração de indicadores fenotípicos para elevar a eficiência do processo de seleção de genótipos superiores de mandioca de mesa em populações segregantes. Na população segregante obtida por meio do cruzamento entre as variedades de mandioca de mesa IAC 576-70 e BRS Japonesa, foi estimada a correlação fenotípica entre sete caracteres agronômicos avaliados individualmente na população de propagação sexual e na população clonal e entre as duas populações. Nenhum caráter na geração de propagação sexual apresentou correlação de elevada magnitude com a produtividade de raízes na geração de propagação clonal. Essa fraca associação entre caracteres na geração de propagação por sementes e o seu potencial produtivo, quando da propagação clonal, revelaram a dificuldade de se prever com acurácia, por meio de avaliações fenotípicas, o potencial produtivo de determinado genótipo precocemente, mesmo quando da sua avaliação a partir de sementes. Entretanto, a associação elevada observada entre o tempo para a cocção na geração de propagação por sementes e na geração de propagação clonal é um indicativo da possibilidade da seleção precoce de clones com baixo tempo para o cozimento.

Palavras-chave: Manihot esculenta Crantz, melhoramento genético, aipim, seleção precoce.

\section{ABSTRACT}

\section{Phenotypic correlation among agronomic traits in a segregating population of sweet cassava}

One of the main barriers for cassava genetic breeding is the difficulty for early selection of superior individuals within the first breeding generations. Therefore, the aim of the present work was to estimate the phenotypic correlations among agronomic characters in a segregating population of sweet cassava, within the vegetative and sexual generation, and between two, in order to obtain phenotypic indicators that increase the efficiency of selection of superior genotypes in segregating populations. The segregating population from the cross IAC 576-70 and BRS Japonesa was used to estimate the phenotypic correlation among seven agronomic traits evaluated individually within the sexual and clonal propagation populations and between the two populations. No trait within the generation of sexual propagation had high correlation with the root yield in the generation of clonal propagation. This weak association among the traits within the seed-propagated generation and their production potential, during clonal propagation, revealed the difficulty to accurately and early predict the production potential of a genotype using phenotypic evaluations, especially when

Recebido para publicação em 22/03/2013 e aprovado em 14/08/2013.

'Trabalho desenvolvido com apoio financeiro da Embrapa, Fundação Banco do Brasil e CNPq

${ }^{2}$ Engenheiro-Agrônomo, Doutor. Embrapa Cerrados, BR 020, Km 18, s/n, 73310-970, Planaltina, Distrito Federal, Brasil. eduardo.alano@embrapa.br (autor para correspondência). ${ }^{3}$ Engenheiro-Agrônomo, Mestre. Embrapa Cerrados, BR 020, Km 18, s/n, 73310-970, Planaltina, Distrito Federal, Brasil. josefino.fialho@embrapa.br

${ }^{4}$ Engenheiro-Agrônomo, Doutor. Embrapa Cenargen, Parque Estação Biológica, Final W5 Norte, s/n, 70770-900, Brasília, Distrito Federal, Brasil. luiz.carvalho@embrapa.br 
evaluating it from seeds. Nevertheless, the high correlation between the cooking time in the seed-propagated generation with the generation of clonal propagation is a parameter to be considered for the early selection of clones with shorter cooking time.

Key words: Manihot esculenta Crantz, plant breeding, sweet cassava, early selection.

\section{INTRODUÇÃO}

O melhoramento genético de mandioca de mesa objetiva a geração de cultivares específicos para a produção de raízes tuberosas para uso culinário nas formas cozida, frita, chips, mandioca palito, pré-cozida, massas, entre outros. Os cultivares para tal fim devem se aliar a baixos teores de ácido cianídrico nas raízes (menos de 100 ppm), elevadas produtividades de raízes com boas qualidades sensoriais (maciez e plasticidade após cozimento, massa não pegajosa, aroma e aparência agradável) e culinárias (poucas fibras, baixo tempo para a cocção e massa cozida homogênea), resistência a pragas e doenças, arquitetura favorável a tratos culturais (não ramifique ou ramifique o mais alto possível), raízes com baixa deterioração póscolheita, precocidade (colheita até 12 meses), entre outras características (Vieira et al., 2011b).

Em razão das características de qualidades culinárias e sensoriais que devem apresentar bons cultivares de mandioca de mesa, devem ser utilizadas estratégias diferenciadas de seleção em populações segregantes (Fukuda et al., 2002; Ceballos et al., 2004; Valle et al., 2004).

O método de melhoramento mais utilizado em mandioca é o que envolve hibridações intraespecíficas entre variedades previamente definidas e, posteriormente, a seleção, de forma massal, de indivíduos superiores dentro das populações segregantes (Fukuda et al., 2002; Ceballos et al., 2004; Vieira et al., 2011b).

Um dos principais entraves do melhoramento genético de mandioca por meio de hibridações intraespecíficas é a dificuldade de seleção de indivíduos superiores na primeira geração do melhoramento, principalmente em razão das grandes diferenças apresentadas pelo sistema radicular de mandioca, quando ela é obtida por sementes, em comparação à multiplicação vegetativa. $\mathrm{O}$ sistema radicular de plantas propagadas sexualmente apresenta uma raiz pivotante e algumas raízes laterais que armazenam amido, diferindo muito do sistema radicular de plantas propagadas vegetativamente (Fukuda et al., 2002; Ceballos et al., 2004). Por essa razão, a identificação de critérios de seleção em populações de propagação sexual que permitam a identificação precoce de indivíduos superiores agilizaria o melhoramento.
Nesse sentido, o conhecimento de correlações fenotípicas entre caracteres avaliados em populações de reprodução sexual e na geração de propagação clonal pode gerar ferramentas que sejam relevantes como indicadores no processo de seleção.

Estudos de melhoramento realizados com populações de mandioca para a indústria de farinha e fécula vêm encontrando baixas correlações entre a produtividade de raízes na geração de propagação clonal e caracteres aferidos na geração de propagação sexual (Bueno, 1983; Fukuda et al., 1987), o que aponta no sentido da dificuldade de identificação precoce de clones produtivos. Em razão dessa baixa correlação, as seleções iniciais em programas de melhoramento vêm se baseando na seleção para caracteres de elevadas herdabilidades como resistência à pragas e doenças, arquitetura da planta, coloração da polpa da raiz, coloração da casca da raiz, entre outros (Fukuda et al., 2002; Ceballos et al., 2004). Entretanto, na literatura não existem relatos de estudos com populações de melhoramento de mandioca de mesa considerando aspectos relacionados à qualidade sensorial e culinária das raízes, como o tempo para a cocção, que é um caráter de grande importância para o mercado de mandioca de mesa.

O objetivo deste trabalho foi estimar correlações fenotípicas entre caracteres agronômicos de interesse em uma população de segregantes de mandioca, nas gerações de propagações vegetativa e sexual e entre as duas, a fim de contribuir na geração de indicadores fenotípicos para elevar a eficiência do processo de seleção de genótipos de mandioca de mesa superiores em populações segregantes.

\section{MATERIAL E MÉTODOS}

Os experimentos foram conduzidos no município de Planaltina (DF), situado a $15^{\circ} 35^{\prime} 30^{\prime \prime} \mathrm{S}$ e $47^{\circ} 42^{\prime} 30^{\prime \prime} \mathrm{O}$, em altitude de $1.000 \mathrm{~m}$, nas safras 2006/2007 (cruzamentos controlados), 2007/2008 (avaliação da população de propagação sexual) e 2008/2009 (avaliação da população de propagação vegetativa e dos genitores).

A população segregante utilizada no estudo foi obtida por meio de cruzamentos controlados utilizando como 
genitor masculino a variedade de mandioca de mesa IAC 576-70, conhecida popularmente na região do Cerrado como Japonesinha, identificada no Banco de Germoplasma de mandioca do Cerrado (BGMC) como BGMC 753, e como genitor feminino a variedade de mandioca de mesa BRS Japonesa, que corresponde ao acesso BGMC 751. Os genitores foram escolhidos em razão de serem indicados para o cultivo na região do Distrito Federal e entorno (Fialho et al., 2009; Vieira et al., 2011c). Os cruzamentos foram realizados entre outubro de 2006 e julho de 2007 , seguindo a metodologia de polinização manual descrita por Fukuda et al. (2002).

Após a polinização manual, os frutos ainda verdes foram envoltos em sacos de algodão e as sementes foram coletadas sistematicamente após sua dispersão natural. Todas as sementes obtidas foram classificadas em sementes verdadeiras e pseudos-sementes, por meio da imersão em recipiente com água à temperatura ambiente. As sementes que flutuaram foram classificadas como pseudossementes e eliminadas, e as verdadeiras foram retiradas da água e secas em condições ambiente.

As sementes verdadeiras foram armazenadas em sacos de papel sob refrigeração a $4{ }^{\circ} \mathrm{C}$, por cerca de 90 dias. Posteriormente, foram dispostas a $2 \mathrm{~cm}$ da superfície no interior de tubetes de polipropileno, com volume de 175 $\mathrm{cm}^{3}$, que foram preenchidos com substrato composto por $1 / 3$ de vermiculita, $1 / 3$ de solo e $1 / 3$ de substrato comercial. Os tubetes foram mantidos em casa de vegetação sob irrigação até 45 dias após a emergência, quando as plântulas foram transplantadas para o campo, em novembro de 2007, em espaçamento de 1,20 entre linhas e 0,80 entre plantas. Os tratos culturais seguiram as recomendações de Fialho \& Vieira (2011).

Em novembro de 2008, aos 12 meses após o transplante para o campo, 98 indivíduos da população de propagação sexual (obtida por meio das sementes), selecionados ao acaso, foram avaliados quanto à massa das raízes em $\mathrm{g}$ (MR); massa da parte aérea em g (MPA); altura da planta em cm (AP); porcentagem de amido nas raízes, obtida por meio do método da balança hidrostática (AM), descrito por Grosmann \& Freitas (1950); e tempo para a cocção em minutos (TC), de acordo com o método descrito por Borges et al. (2002). Foram calculados a massa total da planta em g (MTP), por meio da soma da MR e MPA; e o índice de colheita (IC), por intermédio da razão entre a MR e a MTP.

Todos os 98 indivíduos foram identificados, recebendo numeração de 1 a 98 e replantados a campo em novembro de 2008, empregando-se manivas-sementes (propagação vegetativa) juntamente com os genitores IAC 57670 e BRS Japonesa, ou seja, os indivíduos da geração de população sexual foram clonados.
O plantio foi efetuado em espaçamento de 1,20 entre linhas e 0,80 entre plantas, em que cada clone da população segregante foi representado por uma parcela de cinco plantas e cada genitor por cinco parcelas de cinco plantas. Dessa forma, entre cada 10 clones foram intercaladas, de forma alternada, parcelas dos genitores masculino ou feminino. O preparo do material para o plantio (manivassementes) e os tratos culturais (calagem, adubação e capina) seguiram as recomendações de Fialho \& Vieira (2011). Foram implantadas a campo 98 parcelas dos clones (uma para cada clone) e cinco de cada genitor. Aos 12 meses após o plantio, em novembro de 2009, todas as parcelas foram avaliadas quanto aos mesmos caracteres avaliados na geração de propagação sexual, utilizando-se as três plantas centrais de cada parcela que constituíram a área útil avaliada.

A correlação fenotípica de Pearson entre os caracteres AP, MPA, MR, AM, TC, MTP e IC, avaliados individualmente na população de propagação sexual e na população clonal e entre as duas populações, foi estimada por meio dos valores obtidos na avaliação da população de propagação sexual e dos valores médios da avaliação de cada parcela dos 98 clones na população de propagação vegetativa, sendo a significância da correlação estimada por meio do teste t com a utilização do programa Genes (Cruz, 2001).

\section{RESULTADOS E DISCUSSÃO}

Os resultados revelaram a existência de indivíduos transgressivos na população segregante para todos os caracteres avaliados, tanto na geração de propagação sexual quanto na de propagação vegetativa (Tabela 1), tendo sido identificados genótipos com AP, MPA, MR, AM, IC e MTP superiores aos dos genitores, bem como genótipos com TC inferiores aos dos genitores. Dentre os caracteres considerados mais importantes no melhoramento de mandioca de mesa, além dos baixos teores de ácido cianídrico das raízes e da resistência a pragas e doenças, destacam-se a produtividade de raízes e o tempo para a cocção (Borges et al., 2002; Vieira et al., 2011b), uma vez que a combinação desses caracteres irá refletir a rentabilidade da lavoura e a qualidade culinária das raízes produzidas. Nesse sentido, quanto à produtividade de raízes foram observados ganhos, em relação à média do melhor genitor, de $18 \%$ no melhor genótipo da geração de propagação por sementes e de 59\% no melhor genótipo da geração de propagação clonal. Quanto à redução do tempo para a cocção, foram observados ganhos de 7,5\% nos melhores genótipos de ambas as gerações (Tabela 1).

Esses resultados indicam que a seleção massal de indivíduos transgressivos dentro de populações segregantes é uma estratégia que pode resultar em ganhos genéti- 
cos, como já havia sido relatado por Calle et al. (2005), Cach et al. (2006), Mezette et al. (2009) e Ojulong et al. (2010), e como consequência em retorno econômico para os produtores de mandioca.

O elevado desempenho agronômico médio apresentado pela população segregante é um indicativo da existência de boa complementabilidade genética entre os genitores, o que pode ser explicado pelo fato de apesar dos genitores serem recomendados para o cultivo na região do Distrito Federal, por apresentarem elevado desempenho agronômico e, como consequência, grande similaridade genética quanto a caracteres agronômicos, eles revelam baixa semelhança quanto a caracteres morfológicos e em nível de DNA (Vieira et al., 2011a), o que possivelmente propiciou a geração de uma população segregante superior.

Tabela 1. Média, valor máximo, valor mínimo e amplitude de variação dos caracteres massa de raízes em g (MR), massa de parte aérea em g (MPA), altura da planta em cm (AP), porcentagem de amido nas raízes (AM), tempo para a cocção em minutos (TC), massa total da planta (MTP) e índice de colheita (IC) avaliados em 98 indivíduos de uma população segregante de mandioca nas gerações de propagação sexual por sementes (PS), de propagação clonal por manivas-sementes (PC) e nos genitores masculino IAC 576-70 (GM) e feminino BRS Japonesa (GF)

\begin{tabular}{lcccc}
\hline Caráter & Média & $\begin{array}{c}\text { Valor } \\
\text { máximo }\end{array}$ & $\begin{array}{c}\text { Valor } \\
\text { mínimo }\end{array}$ & Amplitude \\
\hline AP (PS) & 2,11 & 3,35 & 1,43 & 1,92 \\
AP (PC) & 1,97 & 2,80 & 1,26 & 1,54 \\
AP (GM) & 1,94 & 2,06 & 1,83 & 0,23 \\
AP (GF) & 1,80 & 1,91 & 1,61 & 0,30 \\
MPA (PS) & 2390 & 6430 & 370 & 6060 \\
MPA (PC) & 3586 & 8373 & 403 & 7970 \\
MPA (GM) & 4577 & 4780 & 4397 & 383 \\
MPA (GF) & 3699 & 4503 & 3097 & 1406 \\
MR (PS) & 1933 & 4626 & 274 & 4352 \\
MR (PC) & 2605 & 6253 & 400 & 5853 \\
MR (GM) & 3926 & 4347 & 3283 & 1064 \\
MR (GF) & 3201 & 3447 & 3003 & 444 \\
AM (PS) & 25,18 & 34,38 & 18,16 & 16,22 \\
AM (PC) & 26,28 & 30,79 & 19,46 & 11,33 \\
AM (GM) & 28,07 & 28,66 & 27,27 & 1,39 \\
AM (GF) & 28,50 & 29,05 & 28,41 & 0,64 \\
TC (PS) & 27,97 & 40,00 & 14,00 & 26,00 \\
TC (PC) & 25,69 & 40,00 & 14,33 & 25,67 \\
TC (GM) & 22,13 & 26,67 & 18,33 & 8,34 \\
TC (GF) & 18,67 & 20,00 & 16,00 & 4,00 \\
MTP (PS) & 4323 & 10906 & 1014 & 9892 \\
MTP (PC) & 6191 & 14273 & 803 & 13470 \\
MTP (GM) & 8503 & 9127 & 8287 & 840 \\
MTP (GF) & 6900 & 7950 & 6100 & 1850 \\
IC (PS) & 0,46 & 0,72 & 0,27 & 0,45 \\
IC (PC) & 0,43 & 0,70 & 0,18 & 0,52 \\
IC (GM) & 0,46 & 0,50 & 0,43 & 0,07 \\
IC (GF) & 0,47 & 0,49 & 0,43 & 0,06 \\
\hline & & & & \\
\hline
\end{tabular}

Dentro da geração de propagação sexual, o caráter massa de raízes apresentou correlação significativa apenas com os caracteres massa da parte aérea $(r=0,78)$ e com a massa total da planta $(\mathrm{r}=0,91)$, sendo ambas as correlações positivas e elevadas, revelando elevada associação entre esses caracteres (Tabela 2). A massa total da planta teve correlação positiva e significativa também com a massa da parte aérea $(r=0,96)$. Os resultados obtidos foram semelhantes aos relatados com mandioca em populações de propagação sexual por Fukuda et al. (1987) e divergiram sutilmente em relação aos relatados por Bueno (1983) e Ojulong et al. (2010), que encontraram correlações positivas e significativas, porém de baixa magnitude entre a massa de raízes e o índice de colheita.

Esses resultados revelaram que houve clara tendência de os genótipos com maiores produtividades de raízes também apresentarem elevadas produtividades da parte aérea e, por consequência, maior produtividade total de biomassa na geração de propagação sexual. Isso pode ser explicado pelo fato de que os genótipos com maior produtividade de parte aérea serem mais competitivos em razão de possuírem maior número de hastes e folhas e, por consequência, produzirem mais fotoassimilados para serem armazenados nas raízes de reserva e se destacarem mais nas primeiras gerações de seleção, em que existe forte competição intergenotípica em razão da impossibilidade de se controlar o efeito bordadura (Kawano \& Thung, 1982).

O caráter índice de colheita na geração de propagação sexual mostrou correlacionar-se de forma significativa, porém negativa e de baixa magnitude, com a massa total da planta $(\mathrm{r}=-0,36)$ e de moderada magnitude com a massa da parte aérea $(r=-0,55)$ (Tabela 2). Resultado semelhante foi relatado por Fukuda et al. (1987) ao avaliarem duas populações segregantes de mandioca em dois ambientes, o que pode ser explicado pela forma de estimativa do índice de colheita, o qual é resultado da razão entre a massa de raízes e a massa total da planta.

A altura da planta correlacionou-se de forma significativa, porém de baixa magnitude com o índice de colheita $(r=-0,26)$ e a massa da parte aérea $(r=0,22)$, indicando que plantas com elevada estatura tendem a expressar também elevada massa de parte aérea, muito embora a baixa associação entre os caracteres permita inferir ser possível a seleção de indivíduos com elevada estatura e baixa massa da parte aérea e, como consequência direta, com maiores índices de colheita.

O tempo para o cozimento apresentou correlação significativa e negativa apenas com o caráter teor de amido nas raízes $(r=-0,42)$. Essa associação negativa pode ser um indicativo de que o melhoramento de mandioca para duplo propósito (produção de raízes para consumo fresco e utilização na indústria de farinha e fécula) seja possí- 
vel, entretanto mais estudos devem ser conduzidos nesse sentido, incluindo a avaliação de novas populações segregantes.

Na geração de propagação clonal, a massa de raízes correlacionou-se significativamente com a massa total da planta $(r=0,78)$, a massa da parte aérea $(r=0,47)$, a altura de planta $(r=0,25)$, o índice de colheita $(r=0,35)$ e com o teor de amido nas raízes $(r=0,23)$; entretanto, apenas a correlação com a massa total da planta foi de elevada magnitude. Já o caráter massa total de planta apresentou também correlação significativa com massa da parte aérea $(\mathrm{r}=0,92)$, altura da planta $(\mathrm{r}=0,59)$, teor de amido nas raízes $(r=0,27)$ e índice de colheita $(r=-0,27)$, no entanto apenas a correlação com a massa da parte aérea foi de elevada magnitude (Tabela 2).

Os resultados permitem inferir que as plantas mais produtivas foram as que apresentaram maior produtividade total de plantas. Resultados análogos foram relatados por Fukuda et al. (1987) ao avaliarem populações de mandioca em dois ambientes, o que possivelmente seja reflexo direto da maior capacidade de competição dos clones com maior massa total da planta. Resultado interessante foi a associação reduzida, porém positiva entre os caracteres massa de raízes e teor de amido, observada no presente trabalho e que também foi reportada por Fukuda \& Caldas (1987), Fukuda et al. (1987), Calle et al. (2005) e Ojulong et al. (2008), o que aponta a possibilidade da seleção simultânea de clones com elevada produtividade de raízes e maiores teores de amido nas raízes, que é muito importante para o programa de melhoramento de mandioca (Fukuda et al., 2002; Ceballos et al., 2004). Entretanto, resultados contrastantes foram relatados por Cach et al. (2006) e
Ojulong et al. (2010), os quais encontraram correlações negativas porém de baixa magnitude e nula, respectivamente, entre os mesmos caracteres.

A existência de correlação significativa e positiva entre a produtividade de raízes e o índice de colheita em mandioca era esperada, uma vez que o índice de colheita é resultado da razão entre a produtividade de raízes e a massa total da planta e já havia sido relatada em mandioca (Calle et al., 2005; Cach et al., 2006; Gomes et al., 2007; Ojulong et al., 2008; Ojulong et al., 2010).

Na geração de propagação clonal, o caráter índice de colheita também se correlacionou de forma negativa e significativa com os caracteres massa da parte aérea $(\mathrm{r}=-0,61)$ e altura de planta $(\mathrm{r}=-0,44)$, porém de magnitude mediana, resultados semelhantes aos relatados por Cach et al. (2006) e Gomes et al. (2007), o que pode ser explicado pelo modo de cálculo do índice de colheita.

O caráter massa da parte aérea correlacionou-se significativamente também com os caracteres altura da planta $(r=0,67)$ e teor de amido $(r=0,23)$. A correlação positiva e elevada entre a altura de planta e a massa da parte aérea é um indicativo de que as plantas mais altas apresentam maior massa da parte aérea em razão de tenderem a apresentar maior massa de hastes e de folhagem (Cach et al.,2006; Gomes et al., 2007). A associação positiva entre a massa da parte aérea no momento da colheita e o teor de amido nas raízes, muito embora tenha sido de baixa magnitude, é um indicativo de que os clones com maior massa de parte aérea tendem a acumular maior quantidade de amido nas raízes, provavelmente em razão de serem menos prejudicados durante a estação da seca (Cash et al., 2006). No presente trabalho não foi detectada associação

Tabela 2. Correlações fenotípicas entre os caracteres massa de raízes em g (MR), massa de parte aérea em g (MPA), altura da planta em cm (AP), porcentagem de amido nas raízes (AM), tempo para a cocção em minutos (TC), massa total da planta (MTP) e índice de colheita (IC) avaliados em 98 indivíduos de uma população segregante de mandioca nas gerações de propagação sexual por sementes (PS) e de propagação clonal por manivas-sementes (PC)

\begin{tabular}{|c|c|c|c|c|c|c|c|c|c|c|c|c|c|c|}
\hline Caráter & $\begin{array}{c}\mathbf{A P} \\
(\mathbf{P S})\end{array}$ & $\begin{array}{c}\mathbf{A P} \\
(\mathbf{P C})\end{array}$ & $\begin{array}{c}\text { MPA } \\
\text { (PS) }\end{array}$ & $\begin{array}{l}\text { MPA } \\
(\text { PC) }\end{array}$ & $\begin{array}{c}\text { MR } \\
\text { (PS) }\end{array}$ & $\begin{array}{c}\text { MR } \\
(\mathrm{PC})\end{array}$ & $\begin{array}{l}\text { AM } \\
\text { (PS) }\end{array}$ & $\begin{array}{l}\text { AM } \\
\text { (PC) }\end{array}$ & $\begin{array}{c}\text { TC } \\
\text { (PS) }\end{array}$ & $\begin{array}{c}\text { TC } \\
\text { (PC) }\end{array}$ & $\begin{array}{l}\text { MTP } \\
\text { (PS) }\end{array}$ & $\begin{array}{l}\text { MTP } \\
(\text { PC) }\end{array}$ & $\begin{array}{c}\text { IC } \\
\text { (PS) }\end{array}$ & $\begin{array}{c}\text { IC } \\
\text { (PC) }\end{array}$ \\
\hline AP (PS) & 1,00 & & & & & & & & & & & & & \\
\hline $\mathrm{AP}(\mathrm{PC})$ & $0,67^{*}$ & 1,00 & & & & & & & & & & & & \\
\hline MPA (PS) & $0,22^{*}$ & $0,43^{*}$ & 1,00 & & & & & & & & & & & \\
\hline MPA (PC) & $0,37^{*}$ & $0,67^{*}$ & $0,71^{*}$ & 1,00 & & & & & & & & & & \\
\hline MR (PS) & 0,08 & $0,23^{*}$ & $0,78^{*}$ & $0,49^{*}$ & 1,00 & & & & & & & & & \\
\hline MR (PC) & 0,06 & $0,25^{*}$ & $0,32^{*}$ & $0,47^{*}$ & $0,32^{*}$ & 1,00 & & & & & & & & \\
\hline AM (PS) & 0,11 & 0,08 & 0,09 & 0,19 & 0,01 & 0,10 & 1,00 & & & & & & & \\
\hline $\mathrm{AM}(\mathrm{PC})$ & 0,11 & 0,13 & 0,13 & $0,23^{*}$ & 0,05 & $0,23^{*}$ & $0,59^{*}$ & 1,00 & & & & & & \\
\hline TC (PS) & $-0,02$ & 0,13 & 0,08 & 0,12 & 0,09 & 0,07 & $-0,42^{*}$ & $-0,35^{*}$ & 1,00 & & & & & \\
\hline TC (PC) & $-0,01$ & 0,11 & 0,09 & 0,18 & 0,12 & 0,06 & $-0,28^{*}$ & $-0,35^{*}$ & $0,69^{*}$ & 1,00 & & & & \\
\hline MTP (PS) & 0,18 & $0,37^{*}$ & $0,96^{*}$ & $0,66^{*}$ & $0,91^{*}$ & $0,33^{*}$ & 0,06 & 0,11 & 0,08 & 0,11 & 1,00 & & & \\
\hline MTP (PC) & $0,29^{*}$ & $0,59^{*}$ & $0,65^{*}$ & $0,92^{*}$ & $0,49^{*}$ & $0,78^{*}$ & 0,18 & $0,27^{*}$ & 0,11 & 0,16 & $0,62^{*}$ & 1,00 & & \\
\hline $\mathrm{IC}(\mathrm{PS})$ & $-0,26^{*}$ & $-0,37^{*}$ & $-0,55^{*}$ & $-0,43^{*}$ & 0,01 & $-0,14$ & $-0,19$ & $-0,20$ & 0,09 & 0,10 & $-0,36^{*}$ & $-0,37^{*}$ & 1,00 & \\
\hline IC (PC) & $-0,34^{*}$ & $-0,44^{*}$ & $-0,43^{*}$ & $-0,61^{*}$ & $-0,23^{*}$ & $0,35^{*}$ & $-0,11$ & $-0,05$ & $-0,03$ & $-0,15$ & $-0,38^{*}$ & $-0,27^{*}$ & $0,38^{*}$ & 1,00 \\
\hline
\end{tabular}

*Significativo a $5 \%$ de probabilidade de erro pelo teste $t$. 
entre a altura de planta e o teor de amido nas raízes, ao contrário dos resultados de Campos et al. (2004), que relataram a ocorrência de associação elevada e positiva entre esses caracteres. Da mesma maneira como ocorreu na geração de propagação sexual, o tempo para o cozimento apresentou correlação significativa e negativa apenas com o caráter teor de amido nas raízes $(r=-0,35)$, o que reforça a teoria de que o melhoramento de mandioca para duplo propósito é possível em razão dessa associação.

Os coeficientes de correlação entre as gerações de propagações sexual e vegetativa para os caracteres altura da planta $(r=0,67)$, massa da parte aérea $(r=0,71)$ e massa total da planta $(\mathrm{r}=0,62)$ revelaram que é efetiva a seleção já na geração de propagação sexual para esses caracteres, uma vez que as correlações revelaram-se significativas e de moderada a elevada magnitude (Tabela 2).

Tal fato demonstra que a seleção para caracteres relacionados à parte aérea da planta já pode ser efetuada com considerável acurácia desde a geração de propagação sexual, corroborando com Ceballos et al. (2004), que indicaram a eficiência da seleção já na geração de propagação sexual para caracteres relacionados à arquitetura da planta e para resistência à pragas e doenças. Entretanto, esses resultados divergem dos relatados por Bueno (1983), que não detectou correlação significativa entre a massa da parte aérea entre as gerações de propagação sexual e de propagação vegetativa e por Fukuda et al. (1987), que não verificaram correlação elevada entre essas gerações para os caracteres massa da parte aérea e massa total da planta.

Dentre todos os caracteres avaliados na geração de propagação sexual, os únicos que se correlacionaram de forma significativa com a massa de raízes na geração de propagação clonal foram a massa de raízes $(r=0,32)$ e a massa total de planta $(r=0,33)$; entretanto, apesar das correlações terem sido positivas, elas não foram de elevada magnitude (Tabela 2). Esses resultados são semelhantes aos relatados por Fukuda et al. (1987), que observaram também correlações significativas, porém de baixa magnitude, entre esses caracteres em avaliações realizadas em dois locais e divergem dos resultados relatados por Bueno (1983), que mencionou a inexistência de associação significativa entre esses mesmos caracteres. Resultados que apontam no sentido da inexistência de caracteres fenotípicos, a serem avaliados na geração de propagação sexual, que possam prever o potencial produtivo do clone, quando da sua propagação clonal, nos estágios subsequente sde um programa de melhoramento de mandioca.

Além de causas genéticas, esse fato pode ser explicado tanto pela interação genótipo ambiente, uma vez que é impossível a avaliação em um mesmo ano do mesmo clone propagado por sementes e por manivas-sementes, quanto pelas diferenças marcantes entre o sistema radicular de mandioca quando ela é propagada por meio de sementes ou por manivas-sementes, uma vez que as raízes propagadas por sementes apresentam a formação de uma raiz pivotante com armazenamento de amido e algumas raízes de reserva que também armazenam amido, diferindo, sobremaneira, do sistema radicular apresentado pelo mesmo clone quando da sua propagação vegetativa (Fukuda et al., 2002; Ceballos et al., 2004).

Do ponto de vista do melhoramento genético, a fraca associação entre caracteres avaliados na geração de propagação por sementes e o potencial produtivo dos mesmos, quando da propagação clonal, é claro indicativo da dificuldade de se prever com acurácia, por meio de avaliações fenotípicas, o potencial produtivo de determinado genótipo precocemente, ainda quando da sua avaliação do a partir de sementes.

Outro caráter de elevada importância no melhoramento de mandioca de mesa é o tempo para a cocção na geração clonal, que dentre todos os caracteres avaliados na geração de propagação clonal apenas apresentou correlação significativa com o teor de amido nas raízes $(r=-0,28)$ e com o tempo para a cocção na geração sexuada $(r=0,69)$.

Essas correlações dão indícios da possíbilidade de seleção de cultivares de mandioca para duplo propósito (mesa e indústria de farinha e fécula) e para a possibilidade da seleção de clones com baixos tempos para o cozimento de forma precoce na geração de propagação clonal (Tabela 2), o que pode significar em ganho de tempo para programas de melhoramentos de mandioca de mesa.

\section{CONCLUSÃO}

A avaliação de indivíduos na geração de propagação por sementes não é eficiente para prever o seu potencial produtivo quando clonados.

É possível a seleção precoce de indivíduos na geração de propagação por sementes para obter clones com baixos tempos de cozimento.

\section{AGRADECIMENTOS}

À Empresa Brasileira de Pesquisa Agropecuária (Embrapa), à Fundação Banco do Brasil (FBB) e ao Conselho Nacional de Desenvolvimento Científico e Tecnológico (CNPq), pelo apoio financeiro.

\section{REFERÊNCIAS}

Borges MF, Fukuda WMG \& Rossetti AG (2002) Avaliação de variedades de mandioca para consumo humano. Pesquisa Agropecuária Brasileira, 37:1559-1565.

Bueno A (1983) Selection in cassava seedlings. Pesquisa Agropecuária Brasileira, 18:970-1000. 
Cach NT, Lenis JI, Perez JC, Morante N, Calle F \& Ceballos H (2006) Inheritance of useful traits in cassava grow in subhumid conditions. Plant Breeding, 125:177-182.

Calle F, Perez JC, Gaitán W, Morante N, Ceballos H, Llano G \& Alvarez E (2005) Diallel inheritance of relevant trait in cassava (Maninhot esculenta Crantz) adapted to acid-soil savanas. Euphytica, 144:177-186.

Campos MF, Bicudo SJ \& Ono EO (2004) Influência da calagem e do zinco no desenvolvimento das raízes tuberosas da mandioca. Revista Ceres, 51:597-607.

Ceballos H, Iglesias CA, Pérez JC \& Dixon AGO (2004) Cassava breeding: opportunities and challenges. Plant Molecular Biology, 56:503-516.

Cruz CD (2001) Programa genes: aplicativo computacional em genética e estatística. Viçosa, Editora UFV. 648p.

Fialho JF \& Vieira E (2011) Manejo e tratos culturais da mandioca. In: Fialho JF \& Vieira EA (Eds.) Mandioca no Cerrado: orientações técnicas. Planaltina, Embrapa Cerrados. p.60-91.

Fialho JF, Vieira EA, Silva MS, Paula-Moraes SV, Fukuda WMG Santos Filho MOS \& Silva KN (2009) Desempenho de variedades de mandioca de mesa no Distrito Federal. Revista Brasileira de Agrociência, 15:31-35.

Fukuda WMG \& Caldas RC (1987) Correlação entre caracteres morfológicos e agronômicos de mandioca. Revista Brasileira de Mandioca, 6:35-40.

Fukuda WMG, Caldas RC, Mole QMS \& Queiroz GM (1987) Critérios de seleção em populações segregantes de mandioca (Maninhot esculenta Crantz). Revista Brasileira de Mandioca, $6: 41-55$.

Fukuda WMG, Silva SO \& Iglesias C (2002) Cassava breeding. Crop Breeding and Applied Biotechnology, 2:617-638.

Gomes CN, Carvalho SP, Jesus MAS \& Custódio TN (2007) Caracterização morfoagronômica e coeficientes de trilha de caracteres componentes da produção em mandioca. Pesquisa Agropecuária Brasileira, 42:1121-1130.
Grosmann J \& Freitas AG (1950) Determinação do teor de matéria seca pelo método peso específico em raízes de mandioca. Revista Agronômica, 14:75-80.

Kawano K \& Thung MD (1982) Intergenotypic competition and competition with associated crop in cassava. Crop Science, 18:59-63.

Mezette TF, Carvalho CRL, Morgano MA, Silva MG, Parra ESB, Galera JMSV \& Valle TL (2009) Seleção de clones-elite de mandioca de mesa visando a características agronómicas, tecnológicas e químicas. Bragantia, 68:601-609.

Ojulong HF, Labuschagne MT, Fregene M \& Herselman L (2008) A cassava clonal evaluation trial base on new cassava breeding scheme. Euphytica, 160:119-129.

Ojulong HF, Labuschagne MT, Herselman L \& Fregene M (2010) Yield traits as selection índices in seedling populations of cassava. Crop Breeding and Applied Biotechnology, 10:191-196.

Valle TL, Carvalho CRL, Ramos MTB, Mühlen GS \& Villela OV (2004) Conteúdo cianogênico em progenies de mandioca originadas do cruzamento de variedades mansas e bravas. Bragantia, $63: 221-226$

Vieira EA, Fialho JF, Faleiro FG, Bellon G, Fonseca KG, Carvalho LJCB, Silva MS, Paula-Moraes, SV, Oliveira CM \& Denke ML (2011a) Characterization of sweet cassava accessions based on molecular, quantitative and qualitative data. Crop Breeding and Applied Biotechnology, 11:232-240.

Vieira EA, Fialho JF \& Silva MS (2011b) Recursos genéticos e melhoramento da mandioca. In: Fialho JF \& Vieira EA (Ed.) Mandioca no Cerrado: orientações técnicas. Planaltina, Embrapa Cerrados. p.25-35.

Vieira EA, Fialho JF, Silva MS, Paula-Moraes SV, Oliveira CM, Anjos JRN, Rinaldi MM, Fernandes FD \& Guimarães Junior R (2011c) BRS Japonesa: new sweet cassava cultivar for the Distrito Federal region. Crop Breeding and Applied Biotechnology, 11:93-196. 